\title{
Examination of Heritage and Geological Materials Using Correlated Electron- and X-ray-Beam Microanalysis in the SEM
}

\author{
Edward P. Vicenzi ${ }^{1 *}$ and Thomas Lam ${ }^{1}$ \\ 1. Smithsonian Institution, Museum Conservation Institute, Suitland, MD., USA. \\ * Corresponding author: vicenzie@si.edu
}

Laser ablation ICP-MS has become the method of choice for many spatially resolved trace element analytical problems encountered in the Earth sciences [1]. While this technique offers high sensitivity, the mass loss and the disfigurement of the specimen surface is often regarded as a critically limiting factor in the study of heritage objects. Given the value placed upon non-destructive methodologies when examining museum specimens, we have recently implemented micro-x-ray fluorescence spectrometry under high vacuum within the scanning electron microscope (SEM).

In 2018 a Bruker XTrace micro-XRF was fitted to an Hitachi S3700N microscope. A Rh source and one of two polycapillary optics aligned to the electron raster image were used to form a 15 , or $35 \mu \mathrm{m} x$-ray beam (Fig. 1). This spatial resolution is defined as the lateral spot size at Mo $\mathrm{K}_{\alpha}$. A Bruker 6|60 SDD was used to collect $\mathrm{x}$-rays and microanalytical results were computed using the fundamental parameters approach to micro-XRF [2]. The information depth of XRF data scales with the energy of the peak and can be much greater (up to 10s-100s $\mu \mathrm{m}$ ) for high energy X-rays compared to the X-ray emission depths produced by the electron beam [3]. The XRF method therefore serves to complement surface sensitive electron beam microanalysis.

Initial examinations using The ANalytical Dual bEam Microscope (dubbed "Tandem") include lapis lazuli, a lazurite-bearing mineral assemblage, jadetite, and $19^{\text {th }}$ century steel beads used in the manufacture of native American textiles (described here). Electron-excited element imaging illustrates the ferrous beads are partly coated with hydrous corrosion products analogous to terrestrial atmospheric alteration found on iron meteorites, including goethite and akaganéite (Fig. 2) [4]. During the first stage of this new system, XRF analyses were collected in spot mode. Plans to add XRF imaging by way of a substage to raster the specimen at constant velocity under the photon beam are underway. Because the background intensity of an XRF spectrum is greatly reduced relative to electron beam EDS, additional transition metals are measurable at minor and trace element levels (Table 1). One disadvantage to analyzing crystalline samples is that energies corresponding the Bragg reflection angles may appear in the spectrum (Fig. 3). Eucentric rotation in the SEM provides a mechanism to confirm and mitigate such diffraction. Despite this drawback, correlated electron- and x-ray-beam microanalysis offers significant promise regarding a non-destructive approach to constraining the origin and history of precious specimens in Earth, planetary, and heritage sciences.

References:

[1] FE Jenner \& RD Arevalo, Elements 12 (2016), p. 311-316.

[2] M Haschke, "Laboratory Micro-X-Ray Fluorescence Spectroscopy” Springer (2014), 356 p.

[3] M Haschke \& S Boehm, in "Advances in Imaging and Electron Physics" ed. Hawkes (2017) p.1-60.

[4] VF Buchwald \& RS Clarke Jr, American Mineralogist 74 (1989), p. 656-467.

[5] The authors gratefully acknowledge materials received from the reference collection of the National Museum of the American Indian, Smithsonian Institution. 


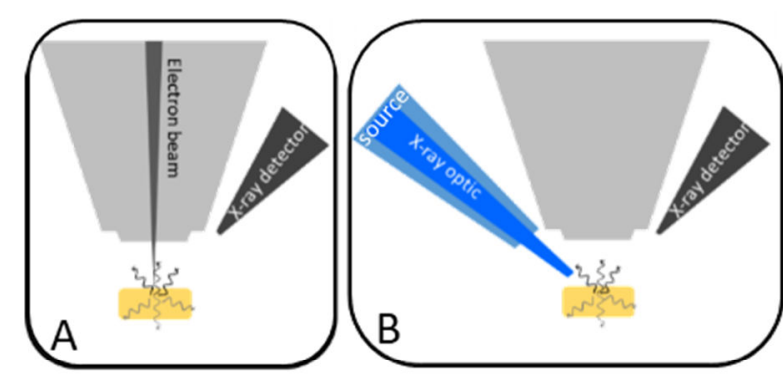

Figure 1. X-ray generation modes in the SEM: A) traditional electron beam excited, and B) Micro-XRF photon source/optic.

Table 1. Steel bead composition determined by micro-XRF.

\begin{tabular}{rc} 
Major & Mass (\%) \\
\hline Fe & 97.31 \\
Minor & Mass \\
\&Trace & $(\mathbf{p p m})$ \\
\hline
\end{tabular}
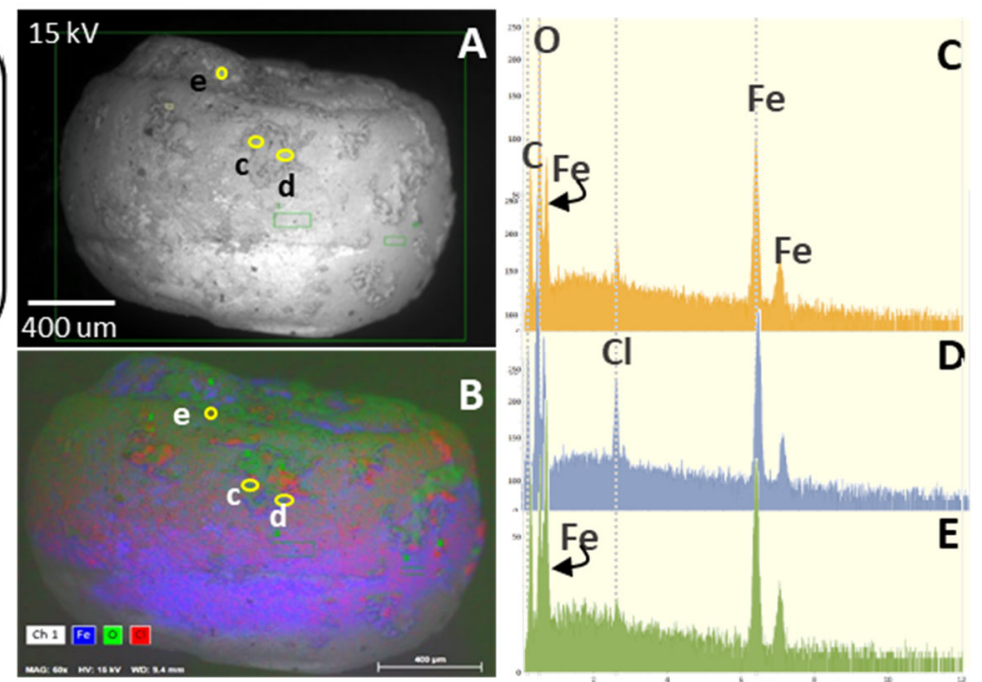

\section{Energy (keV)}

Figure 2. Electron-excited elemental mapping of ferrous bead with derived spectra (sq. root scale) extracted from ellipses. A) backscattered electron image; B) composite X-ray image: $\mathrm{Cl}$ (red), $\mathrm{O}$ (green), $\mathrm{Fe}$ (blue); C) O-rich Fe-C spectrum; D) O-Cl-rich FeC spectrum; E) metallic Fe-C.

$\begin{array}{cl}\mathrm{Al} & 414 \\ \mathrm{Si} & 6706 \\ \mathrm{P} & 450 \\ \mathrm{~S}^{*} & 3503 \\ \mathrm{Cl}^{*} & 5644 \\ \mathrm{Ca} & 881 \\ \mathrm{Mn} & 3067 \\ \mathrm{Co} & 97 \\ \mathrm{Ni} & 906 \\ \mathrm{Cu} & 3876 \\ \mathrm{Zn} & 621 \\ \mathrm{As} & 589 \\ \mathrm{Sn} & 152 \\ \text { ciated } & \text { with surface } \\ \text { sion } & \end{array}$
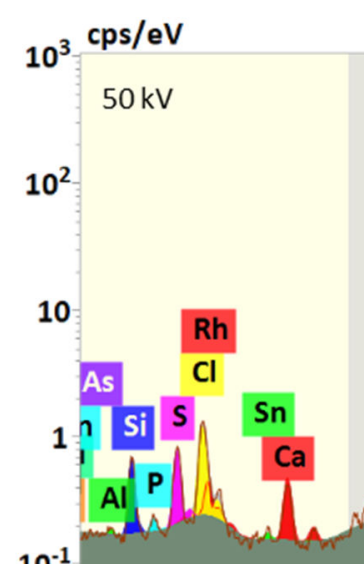

$10^{-1}$
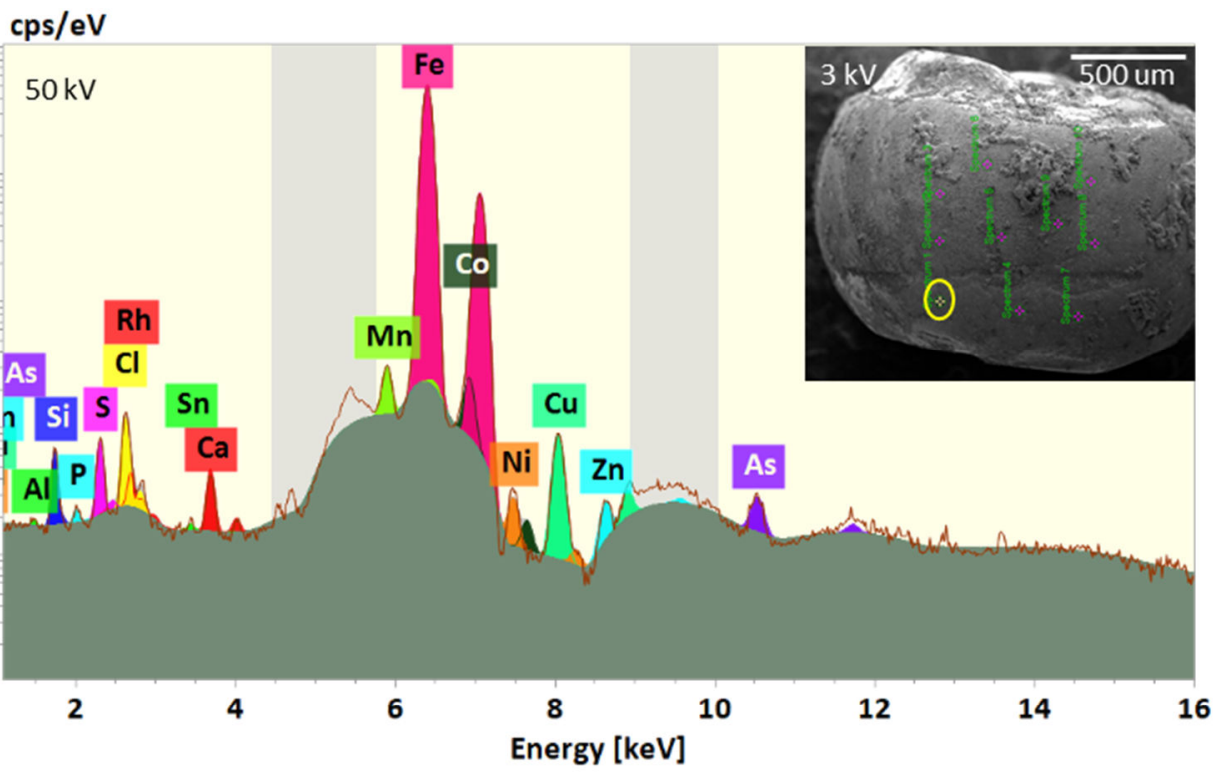

Figure 3. Micro-XRF spectrum (log scale) of ferrous bead collected in a region relatively depleted in surface corrosion products showing Gaussian peak fits for characteristic radiation, diffraction signal (shaded gray regions), and x-ray scattered background. Inset: Secondary electron image of bead in Fig. 2. 